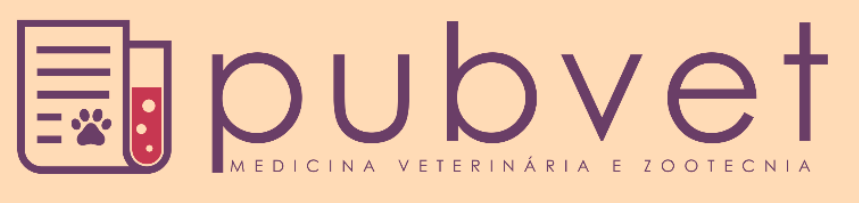

https://doi.org/10.31533/pubvet.v13n9a416.1-8

\title{
Demodicose felina: Revisão
}

\author{
Adriana Leão de Carvalho Lima Gondim*
}

* Médica veterinária graduada pela Universidade Federal Rural de Pernambuco - UFRPE, Pós-graduada em Dermatologia Veterinária de Pequenos Animais pela instituição Qualittas - Universidade Castelo Branco. E-mail: adrianalclg@gmail.com

Resumo. A dermatologia veterinária tem como objetivo atender os animais visando um diagnóstico rápido, preciso e eficaz, a fim de proporcionar a saúde e o bem-estar dos mesmos. A demodicose felina é uma parasitose rara causada por ácaros do gênero Demodex. O objetivo deste trabalho é fazer uma revisão bibliográfica sobre Demodicose Felina, reunindo informações sobre a doença. Para tanto foram colhidas informações relevantes sobre a causa e patogênese da doença, os principais agentes causadores, sinais clínicos, diagnósticos diferenciais, métodos de diagnóstico da doença, fazendo ainda uma explanação sobre os principais protocolos de tratamento utilizados na atualidade, concluindo-se que atualmente ainda não há muito conhecimento sobre a doença quando comparado à Demodicose canina.

Palavras chave: dermatologia, felino, ácaro, demodex, sarna demodécica

\section{Feline Demodicosis: Review}

Abstract. Veterinary dermatology aims to meet the animal's whit a fast, accurate and effective diagnosis to achieve a rapid and efficient in order to provide health and welfare. Feline demodicosis is a rare parasitic disease caused by Demodex mites. The objective of this study is to review the literature about Feline demodicosis, gathering information about this. Therefore, are collected relevant information about the cause and pathogenesis of the disease, the major causative agents, clinical signs, differential diagnosis, methods of diagnosis, making even an explanation of the main treatment protocols used today, concluding that currently there is not much knowledge about the disease when compared to canine demodicosis.

Keywords: dermatology, feline, mite, demodex, demodectic scabies

\section{Demodicosis felina: Revisíon}

Resumen. La dermatología veterinaria tiene como objetivo ayudar a los animales con un diagnóstico rápido, preciso y efectivo para proporcionar salud y bienestar. La demodicosis felina es una parasitosis rara causada por ácaros del género Demodex. El objetivo de este trabajo es hacer una revisión bibliográfica sobre la demodicosis felina, recopilando información al respecto. Para este propósito, se recopiló información relevante sobre la causa y la patogénesis de la enfermedad, los principales agentes causales, signos clínicos, diagnósticos diferenciales, métodos de diagnóstico de la enfermedad, así como una explicación de los principales protocolos de tratamiento utilizados hoy, concluyendo que actualmente Todavía no hay mucho conocimiento sobre la enfermedad en comparación con la demodicosis canina.

Palabras clave: dermatologia, felino, ácaro, demodex, sarna demodéctica 


\section{Introdução}

A pele dos animais é um dos órgãos mais importantes do corpo e possui uma elevada quantidade de funções, entre elas, age como uma barreira eficaz para evitar perda de eletrólitos, água e macromoléculas; age como proteção mecânica contra danos químicos, físicos e microbiológicos, entre outras (Miller et al., 2013). Os ectoparasitos são causadores de dermatopatias nos animais domésticos, acometendo, frequentemente cães e gatos. Dentre as doenças cutâneas de origem parasitaria, estão as acarioses, causadas por ácaros que ocorrem frequentemente em cães e gatos (Hnilica \& Medleau, 2012; Miller et al., 2013).

Demodicose se refere a uma doença cutânea parasitária inflamatória dos cães e gatos causada por proliferação anormal de ácaros do gênero Demodex, que quando presentes em baixo número são considerados parte da fauna normal da pele, sendo a doença clínica mais reconhecida no cão do que no gato (Birchard \& Sherding, 2008). A demodicose felina é considerada uma doença cutânea rara de gato (Ihrke, 2005; Iliev et al., 2019; Kano et al., 2012; Neel et al., 2007; Paterson, 2010; Pereira et al., 2005; Sloss et al., 1999; Urquhart, 1996; Van Poucke, 2001), com prevalência aproximada de quatro casos em cada 10.000 gatos (Bizikova, 2014). Há na literatura poucos relatos de casos (Kano et al., 2012; Löwenstein et al., 2005), sendo descrita por Foley (1995) como a patologia de pele menos comum associada a ácaros em felinos, podendo algumas vezes ser contagiosa (Ihrke, 2005). Casos da doença foram relatados por Silbermayr et al. (2013) e Bizikova (2014).

Os ácaros demodex são comensais da pele felina normal (Ihrke, 2005). Foram identificadas duas espécies diferentes desses ácaros: Demodex gatoi e Demodex cati, estando este último geralmente associado a doenças subjacentes (Ihrke, 2005; Kano et al., 2003; Pereira et al., 2005; Urquhart, 1996) tais como infecções virais e doenças endócrinas como diabetes melito e hiperadrenocorticalismo (Paterson, 2010), assemelhando-se bastante a infecção por Demodex canis em cães (Ihrke, 2005). Segundo Guaguère \& Bensignor (2005) as infecções por Demodex cati também são atribuídas a animais imunosuprimidos ou em consequência da administração de tratamentos imunossupressores. O Demodex cati vive nas unidades pilosebáceas, ou seja, nos folículos pilosos, glândulas e ductos sebáceos (Beale, 2012; Guaguère \& Bensignor, 2005; Nuttal, 2010) ocasionando a demodicose folicular ou localizada (Nuttal, 2010; Pereira et al., 2005); enquanto o Demodex gatoi se localiza na epiderme superficial e é contagioso (Guaguère \& Bensignor, 2005; Nuttal, 2010), causando dermatopatia pruriginosa (Hnilica $\&$ Medleau, 2012), sendo responsável pela demodicose superficial ou generalizada (Pereira et al., 2005). Segundo Desch Juniorr \& Stewart (1999) e Silbermayr et al. (2013) existe um relato de uma terceira espécie ainda não identificada e, ainda, segundo Löwenstein et al. (2005) infecções concomitantes das duas espécies citadas anteriormente já foram descritas na literatura. As infecções por Demodex cati são mais sérias do que as infecções causadas pelas outras espécies de Demodex (Jeromin, 2004).

Não está claro por que razão os ácaros provocam a doença em uns gatos e em outros não (Nuttal, 2010). Seu ciclo de vida e modo de transmissão ainda não estão bem elucidados (Guaguère \& Bensignor, 2005). Segundo Sloss et al. (1999) e Nuttal (2010) esses ácaros vivem e completam seu ciclo vital nos folículos capilares e glândulas sebáceas do hospedeiro e as infecções por Demodex não produzem sinais clínicos na maioria dos animais infectados. Alguns autores têm descrito a infecção por Demodex gatoi como um processo contagioso que ocorre em vários gatos da mesma população felina ao mesmo tempo (Moriello, 2014).

Segundo Nuttal (2010) não existe predisposição de idade, sexo nem raça aparente para que o animal venha a apresentar sintomas da doença; porém, segundo Guaguère \& Bensignor (2005) siameses e burmeses têm maior predisposição e segundo Scott (1980) e Birchard \& Sherding (2008) a maioria dos casos ocorre em animais idosos.

\section{Morfologia dos ácaros e aspecto clínico da doença}

O Demodex cati possui morfologia similar ao Demodex canis (Beale, 2012). Segundo Young (2010), em comparação ao Demodex cati, o Demodex gatoi (Figura 1) é um ácaro mais curto que vive no extrato córneo bem mais superficialmente do que o Demodex cati, que vive nos folículos pilosos. Microscopicamente, o Demodex gatoi, tem a metade do comprimento do Demodex cati e sua cauda é mais arredondada. 


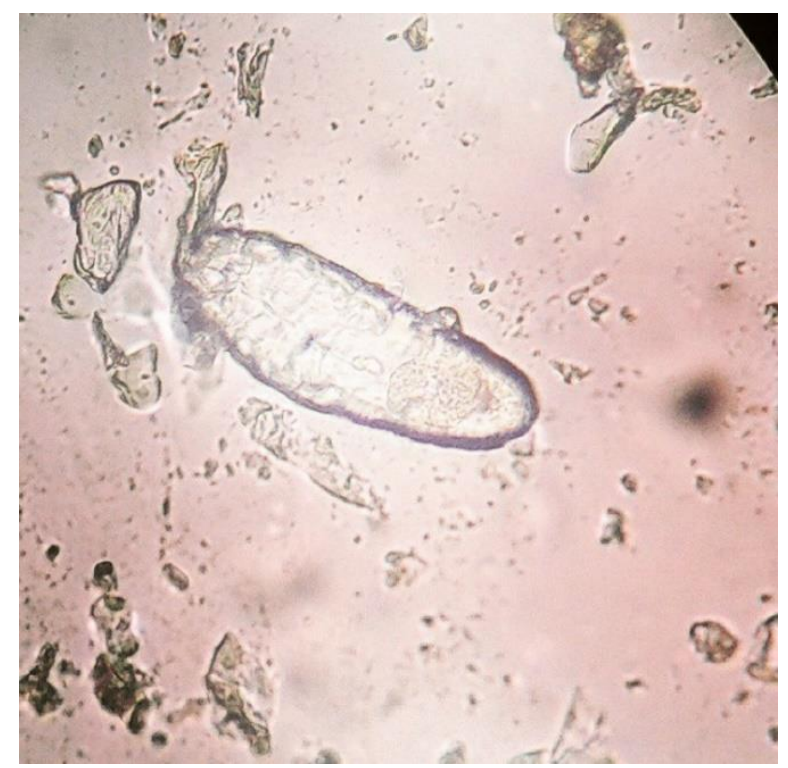

Figura 1. Microscopia [100x] do ácaro Demodex gatoi (forma adulta) obtido em raspado cutâneo.

Uma ampla variedade clínica da doença é percebida (Gross et al., 2009). São identificadas as formas localizada e generalizada da doença, sendo o prurido considerado variável em ambas as formas (Paterson, 2010).

$\mathrm{Na}$ doença localizada observa-se frequentemente alopecia dispersa com eritema e caspa acometendo a face e a cabeça do animal (Hnilica \& Medleau, 2012; Paterson, 2010) especialmente as pálpebras e pele periocular (Paterson, 2010), podendo ainda ocorrer como otite externa ceruminosa pruriginosa (Beale, 2012; Hnilica \& Medleau, 2012; Paterson, 2010; Scott et al., 1996). O prurido pode estar presente ou não e em alguns animais pode-se observar traumatismo auto induzido por mordeduras (Gross et al., 2009; Ihrke, 2005; Scott, 1980). Na doença generalizada estão presentes lesões como máculas multifocais variavelmente pruriginosas, com prurido variando de ausente a extremo, áreas de alopecia simétricas, assimétricas, regionais ou multifocais, hiperpigmentação, eritema e descamação, acometendo a cabeça, o pescoço, o tronco, os membros e o ventre (Hnilica \& Medleau, 2012; Ihrke, 2005; Patel \& Forsythe, 2011; Paterson, 2010).

\section{Diagnóstico diferencial}

Os diagnósticos diferenciais da sarna demodécica felina devem incluir todas as doenças felinas que se manifestam sob a forma de prurido (Gross et al., 2009). Os principais diagnósticos diferenciais são dermatofitose, síndrome foliculite-furunculose bacteriana, alopecia psicogênica, dermatite atópica, alergia alimentar, dermatite por contato, dermatite alérgica a picada de pulga (DAPP), infestação por Cheyletiella, Notoedres, Otodectes, Sarcoptes e certas espécies de piolho (Guaguère \& Bensignor, 2005). Paterson (2010) cita ainda como diagnóstico diferencial as neoplasias cutâneas.

\section{Diagnóstico clínico e laboratorial}

O diagnóstico é feito em um primeiro momento através da anamnese e sinais clínicos (Paterson, 2010). Os exames laboratoriais de eleição são os raspados profundos (Figura 2) e superficiais a procura de ácaros adultos, ovos, larvas e ninfas. No caso do Demodex cati o diagnóstico é feito através de raspados cutâneos. Por se tratar de um ácaro folicular deve-se realizar raspados profundos e em geral os ácaros são fáceis de encontrar, ainda que em alguns casos, seu número seja baixo (Chesney, 1989). Demodex gatoi pode ser difícil de encontrar nos raspados, apesar de sua localização ser mais superficial (Takle \& Hnilica, 2004). Pode ainda ser realizado esfregaço por decalque em fita de acetato (Figura 3) para identificar ácaros superficiais de Demodex gatoi (Hnilica \& Medleau, 2012; Paterson, 2010); porém, segundo Nuttal (2010) espremer a pele pode obrigar os ácaros a sair para a superfície antes da coleta. O arrancar de pelos é mais sensível e pode ser útil em animais muito nervosos e para lugares do corpo de onde seja difícil conseguir um raspado (Paterson, 2010). Raspados cutâneos obtidos de gatos 
com prurido excessivo podem não apresentar o ácaro ou seus ovos, visto que o hábito de autocuidado excessivo dos felinos costuma eliminar tais organismos da superfície cutânea. Em contrapartida, raspados obtidos de gatos que não apresentam pruridos, geralmente revelam uma grande quantidade de ácaros e ovos (Gross et al., 2009). Pode ser difícil realizar um raspado de lesões com grande cicatrização, ulceração ou drenagem, porém espremer a lesão obriga o material purulento e os ácaros saírem para a superfície de onde são recolhidos (Nuttal, 2010). Segundo Scott et al. (1996) os raspados cuidadosos de pele são fundamentais para fazer um diagnóstico adequado. Para a forma otológica da doença é indicado a otoscopia e realização de parasitológico de secreção auricular com swab (Figuras 4 e 5) quando presente (Van Poucke, 2001). Em alguns casos, quando há uma elevada suspeita da existência da doença e não é possível observar ácaros devido aos hábitos de higiene e lambedura dos gatos, pode-se realizar parasitológico de fezes, analisando a amostra pela técnica da flutuação fecal, onde é possível encontrar os ácaros para diagnóstico da infecção por Demodex gatoi (Moriello, 2014).

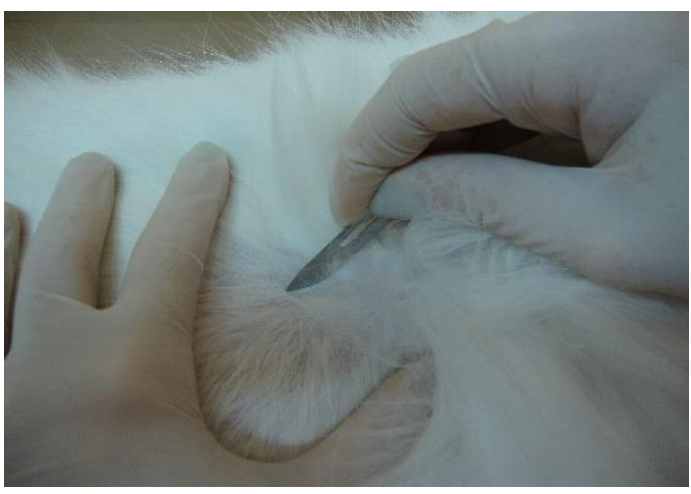

Figura 2. Realização de raspado cutâneo profundo em felino

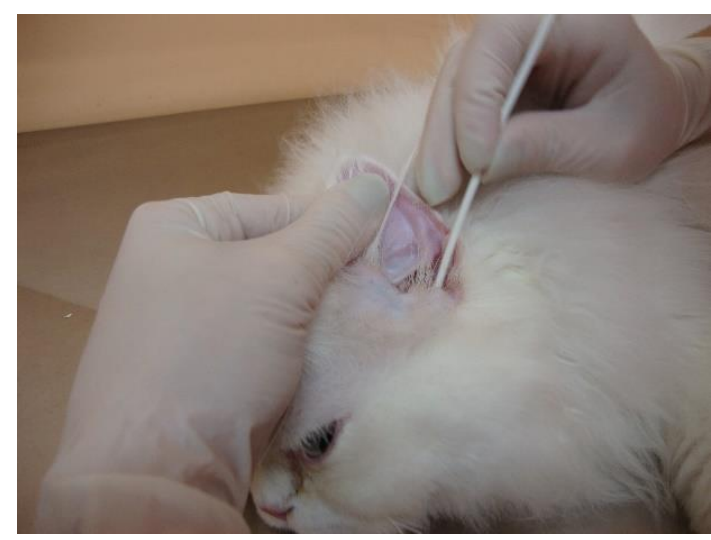

Figura 4. Realização de coleta de secreção auricular Com swab em felino

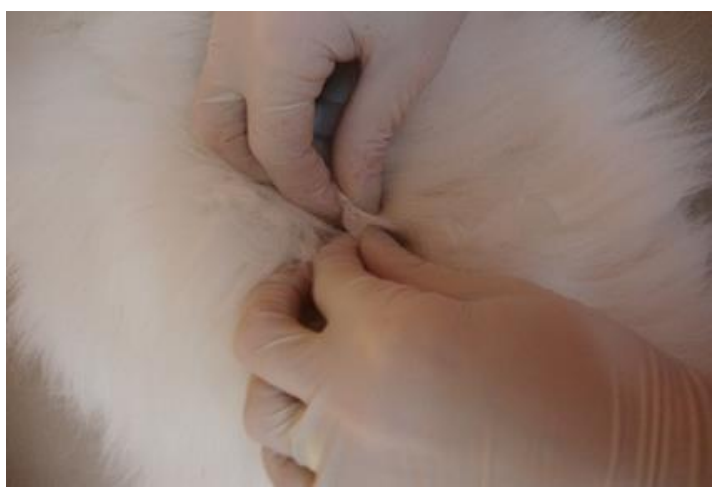

Figura 3. Realização de decalque com fita de acetato em felino

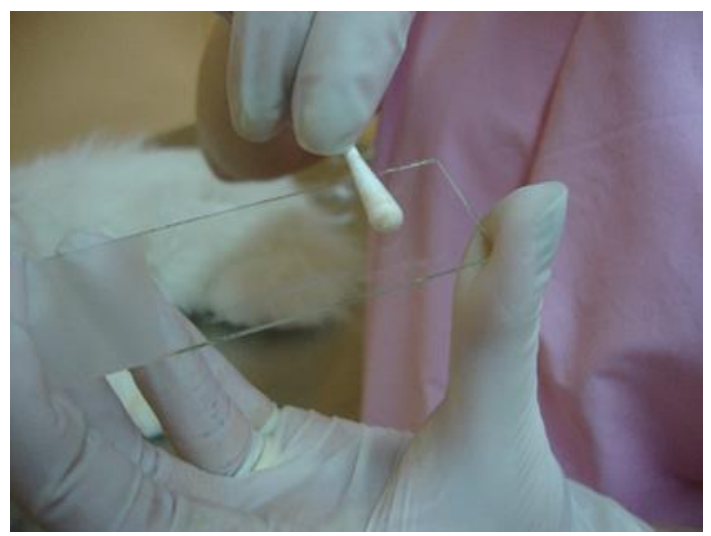

Figura 5. Preparo da amostra para realização de parasitológico de secreção auricular de felino

Paterson (2010) cita ainda como forma de diagnóstico que o ensaio terapêutico utilizando banhos semanais com cal de enxofre em conjunto com a anamnese e sinais clínicos são frequentemente indicado para se diagnosticar infecções por Demodex gatoi e Hnilica \& Medleau (2012) afirmam que uma das formas de diagnóstico é avaliar a resposta aos banhos com polissulfatos de enxofre aplicados semanalmente.

A biópsia de pele (dermato-histopatologia) revela dermatite perivascular supurativa com ácaros presentes no extrato córneo e folículos, graus variáveis de perifoliculite, foliculite e furunculose podem ser observados (Hnilica \& Medleau, 2012; Patel \& Forsythe, 2011; Paterson, 2010) e é indicada sempre que os ácaros sejam encontrados. Além disso, a biópsia pode elucidar uma demodicose felina que não foi suspeitada clinicamente, pois muitos clínicos dificilmente suspeitam das diversas formas de apresentação dessa doença (Gross et al., 2009). As regiões menos inflamadas e áreas em que tem mais dificuldade de se lamber são ideias para a biópsia. Diversas amostras devem ser coletadas para que se aumente a probabilidade de se encontrar os ácaros (Gross et al., 2009). Na histopatologia, em alguns casos de demodicose superficial felina a inflamação é mínima e acompanhada de acantose e hiperceratose lamelar. Os ácaros estão dispersos entre a camada de ceratina (Gross et al., 2009). Scott 
et al. (1996) afirmam que nenhum ácaro foi encontrado nos folículos pilosos. Em outros casos, provavelmente naqueles que se correlacionam com o prurido clínico, notam-se erosão e ulceração epidérmica, além de crostas com um infiltrado inflamatório, que varia de perivascular a difuso e é composto de linfócitos, histiócitos eosinófilos e mastócitos. O diagnóstico definitivo é facilmente obtido se os ácaros forem identificados nos tecidos (Gross et al., 2009).

\section{Tratamentos}

Nenhum medicamento está aprovado para tratamento de sarna demodécica no gato (Paterson, 2010). Alguns gatos respondem espontaneamente, em curto prazo, a medicamentos como banhos tópicos de enxofre sodado, xampus de carbaril, aplicações de malation e rotenona (Scott et al., 1996). A facilidade aparente com que a demodicose generalizada pode ser tratada em alguns gatos pode ser explicada pela localização frequentemente superficial dos ácaros na pele dos gatos, quando comparada àquela da pele dos cães (Paterson, 2010). Segundo Scott et al. (1996) o tratamento com aplicação de Amitraz a 125 ou 250 ppm em base semanal também pode ser benéfico; porém, Nuttal (2010) afirma que o uso de Amitraz não está autorizado em gatos e caso seja utilizado, a concentração é a metade da recomendada pelo fabricante do produto para cães. Efeitos adversos do uso em concentrações aumentadas consistem em sedação, salivação, anorexia, depressão e diarreia. Ihrke (2005) cita que nenhum tratamento para demodicose generalizada é $100 \%$ eficaz, porém há muitas opções de tratamento. A resposta clínica depende do estado imune do gato. Todos os fatores predisponentes devem ser identificados e tratados (Nuttal, 2010; Paterson, 2010).

O protocolo de tratamento citado por Paterson (2010) para infecções por Demodex gatoi consiste em aplicações de cal de enxofre $2-4 \%$ a cada 3 a 7 dias por 4 a 8 semanas; porém, para Hnilica \& Medleau (2012) esse intervalo deve ser de sete dias durante 1 a 2 semanas. Nuttal (2010) cita o intervalo de 4-6 semanas. Os gatos geralmente melhoram durante as primeiras quatro semanas, mas o tratamento deve continuar por um total de 6-8 semanas (Paterson, 2010). Segundo Nuttal (2010) os banhos devem ser mantidos até se obter um resultado negativo no raspado cutâneo. Ihrke (2005) cita que o tratamento com banhos semanais com enxofre é o mais recomendado para felinos. Pode também ser utilizado a Milbemicina e Ivermectina; porém, os relatos são empíricos (Paterson, 2010).

Hnilica \& Medleau (2012) citam que se deve manter o tratamento até a cura das lesões e a negatividade dos raspados cutâneos. Segundo Nuttal (2010) e Paterson (2010) para as lesões generalizadas ainda pode se usar a Doramectina, administrada por injeção na dose de $0,6 \mathrm{mg}$ por kg por via subcutânea, semanalmente. Nuttal (2010) cita que a Doramectina teve uma boa resposta e boa tolerância quando foi utilizada em três gatos portadores de demodicose; porém, Löwenstein et al. (2005) relatam um caso em que um felino foi tratado inicialmente com Ivermectina na dose de $300 \mu \mathrm{g}$ (microgramas) por via oral a cada vinte e quatro horas, sendo em seguida o tratamento continuado com Doramectina na dose de $0,6 \mathrm{mg}$ por kg e após a segunda aplicação o gato apresentou-se muito letárgico e anoréxico, sendo encaminhado para eutanásia.

Para as infecções causadas por Demodex cati, Paterson (2010) afirma que o tratamento precisa ser aplicado por 3-4 semanas e até que resolução clínica dos sinais seja observada e sejam obtidos raspados cutâneos negativos. Segundo Hnilica \& Medleau (2012) as lesões localizadas podem se curar espontaneamente, sem tratamento. Paterson (2010) recomenda que para lesões localizadas, o Amitraz $0,015-0,025 \%$ podem ser eficazes quando aplicado diariamente nas lesões até a resolução clínica. Hnilica \& Medleau (2012) cita que essa solução deve ser preparada no momento do uso. Van Poucke (2001) relata um caso onde se utilizou para o tratamento de um felino diagnóstico com otite externa ceruminosa causada por Demodex cati inicialmente a aplicação de um acaricida tópico três vezes ao dia, após seis semanas de tratamento observou-se melhora clínica no paciente, não sendo mais visualizados ácaros à microscopia, posteriormente houve recidiva dos sinais clínicos e da infestação por ácaros, sendo então realizado tratamento auricular tópico com Ivermectina bovina $1 \%$ uma vez ao dia e seis semanas após o tratamento os ácaros não foram mais encontrados. Após um ano e cinco meses do início do tratamento, o paciente veio a apresentar sinais de inapetência, letargia e desidratação e à palpação abdominal pôde-se observar o fígado aumentado de tamanho com nódulos em sua superfície e o proprietário optou por realizar a eutanásia do paciente. Iliev et al. (2019) relatam a realização de tratamento com aplicações subcutâneas semanais de Doramectina na dose de $300 \mu \mathrm{g} / \mathrm{kg}$ durante oito 
semanas associando antibioticoterapia sistêmica com Amoxicilina e Clavulanato por via oral, na dose de $12,5 \mathrm{mg} / \mathrm{kg}$, dividido em duas doses diárias por 3 semanas, além de Cetirizina por via oral na dose de 2,5 mg uma vez ao dia em um felino infectado concomitantemente por ácaros Demodex cati e pelo Vírus da Imunodeficiência Felina, não sendo observados mais ácaros e havendo melhora geral da condição clínica do paciente após trinta dias de tratamento. Porém, após um ano, houve recorrência da infecção com manifestações clínicas ainda mais severas, o mesmo tratamento foi prescrito, havendo desaparecimento de todos os sinais clínicos novamente. Após seis meses da segunda manifestação clínica da doença, houve, mais uma vez, o aparecimento dos sinais clínicos e o paciente apresentou piora progressiva de sua condição geral, inapetência, diarreia, perda de peso, gengivite, sintomas respiratórios e alteração do comportamento, não sendo aplicado nenhum tratamento e o proprietário optou pela eutanásia do paciente.

\section{Prognóstico}

Quando a infestação pelo ácaro é a única doença existente o prognóstico é favorável, já que os casos geralmente respondem a tratamentos simples como três aplicações de solução de malation ou enxofre sodado com intervalos semanais (Scott et al., 1996). A existência de doenças subjacentes faz com que o prognóstico seja desfavorável em animais adultos e em casos de demodicose generalizada (Nuttal, 2010). Segundo Paterson (2010) a demodicose felina localizada tem um prognóstico favorável, enquanto a demodicose generalizada tem um prognóstico bom a reservado, dependendo de quaisquer fatores imunossupressores que estejam presentes e se forem sensíveis a tratamento.

\section{Discussão}

A grande maioria dos autores concorda que a Demodicose felina é uma doença rara em gatos, causada por duas espécies de ácaros, o Demodex cati e o Demodex gatoi; porém, Desch Juniorr \& Stewart (1999) e Silbermayr et al. (2013) citam que existe uma terceira espécie de ácaro ainda não identificada. A maioria dos autores concorda sobre os sinais clínicos, tipos de lesões observadas na pele dos felinos acometidos e principais diagnósticos diferenciais da Demodicose felina.

Segundo Scott et al. (1996) o tratamento com aplicação de Amitraz em base semanal também pode ser benéfico; porém, Nuttal (2010) afirma que o uso de Amitraz em felinos não está autorizado em gatos. O tratamento mais recomendado pelos autores é a utilização de banhos semanais com cal de enxofre 2$4 \%$; porém, estes mesmos autores divergem quanto ao tempo de tratamento, variando de uma a oito semanas. Nuttal (2010) afirma que o tratamento com Doramectina tem boa tolerância, porém em um caso relatado por Löwenstein et al. (2005) no qual o tratamento foi feito inicialmente com Ivermectina e em seguida continuado com Doramectina, assim como no caso relatado por Van Poucke (2001) no qual também se utilizou tratamento à base de Ivermectina bovina $1 \%$ e no caso relatado por Iliev et al. (2019) no qual foi utilizada Doramectina, o pacientes apresentaram recidiva dos sinais clínicos e piora de sua condição clínica geral após tempos variados do tratamento, sendo todos encaminhados para eutanásia. Para o tratamento da otite ceruminosa não foram encontrados protocolos em literatura, apenas um relato de um caso onde foi utilizado Ivermectina tópica. Os autores concordam que o prognóstico é favorável na forma localizada e reservado na forma generalizada, tornando-se desfavorável em animais adultos que tenham alguma doença subjacente.

\section{Conclusão}

Para qualquer dermatopatia apresentada pelo paciente é necessário a realização de uma anamnese minuciosa, além da realização de exames complementares, observando sempre a técnica correta a ser utilizada no momento da obtenção das amostras para que se possa chegar a um diagnóstico correto. $\mathrm{O}$ conhecimento sobre as doenças que afetam a pele é de extrema importância para a realização de um tratamento adequado e seguro para o paciente.

A demodicose felina é uma doença considerada rara, sobre a qual ainda não se conhece claramente o mecanismo e difícil de ser diagnosticada, diminuindo ainda mais a probabilidade de visualização dos ácaros se o profissional não tiver conhecimento sobre a técnica adequada para coleta das amostras dos pacientes, ocasionando muitas vezes falhas no diagnóstico. A maioria dos tratamentos utilizados para a 
demodicose felina ainda oferecem riscos ao paciente, devendo o mesmo ser acompanhado atenciosamente por um médico veterinário durante todo o tratamento.

\section{Referências bibliográficas}

Beale, K. (2012). Feline demodicosis: a consideration in the itchy or overgrooming cat. Journal of Feline Medicine and Surgery, 14(3):209-213.

Birchard, S. J. \& Sherding, R. G. (2008). Manual Saunders: clínica de pequenos animais (Vol. 3). São Paulo.

Bizikova, P. (2014). Localized demodicosis due to Demodex cati on the muzzle of two cats treated with inhalant glucocorticoids. Veterinary Dermatology, 25(3):222-e258.

Chesney, C. J. (1989). Demodicosis in the cat. Journal of Small Animal Practice, 30(12):689-695.

Desch Juniorr, C. E. \& Stewart, T. B. (1999). Demodex gatoi: new species of hair follicle mite (Acari: Demodecidae) from the domestic cat (Carnivora: Felidae). Journal of Medical Entomology, 36(2):167-170.

Foley, R. H. (1995). Feline Demodicosis. Compendium on Continuing Education, 17481-486.

Gross, T. L., Ihrke, P. J., Walder, J. E. \& Affolter, K. V. (2009). Doenças de pele do cão e do gato: diagnóstico clínico e histopatológico. São Paulo: Roca.

Guaguère, E. \& Bensignor, E. (2005). Terapêutica dermatológica do cão (Vol. 1). São Paulo, Brasil: Roca.

Hnilica, K. A. \& Medleau, L. (2012). Dermatologia de pequenos animais: atlas colorido e guia terapêutico. Rio de Janeiro, Rio de Janeiro, Brasil. : Roca.

Ihrke, P. J. (2005). Canine and feline demodicosis. Paper presented at the Proceedings of the NAVC North American Veterinary Conference.

Iliev, P. T., Zhelev, G., Ivanov, A. \& Prelezov, P. (2019). Demodex cati and feline immunodeficiency virus co-infection in a cat. Bulgarian Journal of Veterinary Medicine, 22(2):237-242.

Jeromin, A. (2004). Why my cat scratching its face. The News Magazine of Veterinary Medicine, 351-4.

Kano, F. S., Shimada, M. T., Suzuki, S. N., Osaki, S. C., Menarim, B. C., Ruthes, F. R. V. \& Laidane Filho, M. A. (2003). Ocorrência da dioctofimose em dois cães no município de Guarapuava-PR. Semina: Ciências Agrárias, 24(1):177-180.

Kano, R., Hyuga, A., Matsumoto, J., Nogami, S., Nemoto, S., Hasegawa, A. \& Kamata, H. (2012). Feline demodicosis caused by an unnamed species. Research in Veterinary Science, 92(2):257-258.

Löwenstein, C., Beck, W., Bessmann, K. \& Mueller, R. S. (2005). Feline demodicosis caused by concurrent infestation with Demodex cati and an unnamed species of mite. Veterinary Record, 157290-292.

Miller, W. H., Griffin, C. E., Campbell, K. L. \& Muller, G. H. (2013). Muller and Kirk's Small Animal Dermatology. Philadelphia, USA: Elsevier Health Sciences.

Moriello, K. (2014). Feline dermatophytosis: aspects pertinent to disease management in single and multiple cat situations. Journal of Feline Medicine and Surgery, 16(5):419-431.

Neel, J. A., Tarigo, J., Tater, K. C. \& Grindem, C. B. (2007). Deep and superficial skin scrapings from a feline immunodeficiency virus-positive cat. Veterinary Clinical Pathology, 36(1):101-104.

Nuttal, T. (2010). Enfermedades cutaneas del perro y el gato. Grupoasis, Zaragoza, Espanha.: Grupoasis, Zaragoza, Espanha.

Patel, A. \& Forsythe, P. J. (2011). Dermatologia em pequenos animais. Rio de Janeiro: Elsevier Brasil.

Paterson, S. (2010). Manual de doenças da pele do cão e do gato. Rio de Janeiro, Rio de Janeiro, Brasil.: Guanabara Koogan.

Pereira, S. A., Pacheco, S. T. M., Borges, F. F., Paes Leme, L. R., Barbieri, S. I., Okamoto, T., . . . Schubach, A. (2005). Demodicose associada à Esporotricose e Pediculose em gato co-infectado por FIV/FeLV. Acta Scientiae Veterinariae, 33(1):75-78.

Scott, D. W. (1980). Feline dermatology 1900-1978: a monograph. Journal of the American Animal Hospital Association, 16(3):331-459. 
Scott, D. W., Muller, G. H. \& Kirk, R. W. (1996). Dermatologia dos pequenos animais (Vol. 1). Rio de Janeiro: Interlivros.

Silbermayr, K., Joachim, A., Litschauer, B., Panakova, L., Sastre, N., Ferrer, L. \& Horvath-Ungerboeck, C. (2013). The first case of Demodex gatoi in Austria, detected with fecal flotation. Parasitology Research, 112(8):2805-2810.

Sloss, M. W., Zajac, A. \& Kemp, R. (1999). Parasitologia clínica veterinária (2a Ed. ed.). Rio de Janeiro: Guanabara Koogan.

Takle, G. L. \& Hnilica, K. A. (2004). Eight emerging feline dermatoses. Veterinary Medicine, 1456-468.

Urquhart, G. M. (1996). Parasitologia veterinária (2 ed.). Rio de Janeiro: Guanabara Koogan.

Van Poucke, S. (2001). Ceruminous otitis externa due to demodex cati in a cat. Veterinary Record, 149651-652.

Young, S. (2010). Feline demodicosis: prevalence, diagnostics, treatment: overview of two Demodex species thar affect cats in very different ways. DVM News Magazine of Veterinary Medicine, 411-8.

Recebido: 3 de setembro, 2019.

Aprovado: 2 de outubro, 2019.

Publicado: 25 de outubro, 2019.

Licenciamento: Este artigo é publicado na modalidade Acesso Aberto sob a licença Creative Commons Atribuição 4.0 (CC-BY 4.0),

a qual permite uso irrestrito, distribuição, reprodução em qualquer meio, desde que o autor e a fonte sejam devidamente creditados 